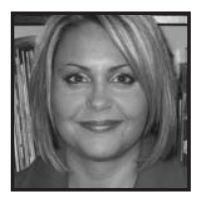

\title{
How a Therapy Dog May Inspire Student Literacy Engagement in the Elementary Language Arts Classroom
}

\author{
Lori Friesen, University of Alberta
}

\begin{abstract}
In this article, I discuss theoretical possibilities for the inclusion of therapy dogs in the elementary language arts classroom, particularly which may inspire students otherwise reluctant to engage in literacy activities. I incorporate Guthrie and colleagues' work in engagement into research in Animal Assisted Therapy with children to posit a revised theory of engagement.
\end{abstract}

$t$ was October, and my grade 2 students gathered around in what seemed to be breathless anticipation to meet my new little white Maltese-poodle puppy, Tango. Before I invited her out of her kennel, as a class we reviewed what we had researched and learned over the past two weeks about how to meet a new dog: stay seated and let the puppy come to you, put your hand out, palm-down to let her sniff you before petting her on her back or side. Ensure that you are gentle and quiet, because the puppy is little and may be afraid, just like us, if she hears sudden, loud noises. We had removed our shoes in a class decision to prevent accidental injury to one of her tiny paws, and student volunteers had placed fresh water and a blanket on the floor nearby. Finally, the moment the students had been preparing for had come.

As Tango pounced out of her kennel and seemingly into the hearts of my students, I became increasingly aware of her potential for engaging young learners in my classroom. She seemed to instantly connect with the children; the atmosphere was one of warmth and joy, of care and empathy for this tiny puppy. My students had been busy 
researching, reading, and learning about puppies in purposeful anticipation of this first visit; their urgent questions now were how long could she stay, and when could she come back again? As I observed my students interacting with her, I began to wonder: In what other ways might this little dog inspire student literacy engagement in our classroom?

Literacy skills are a prerequisite for success in life, yet millions of children in North America are not reading at grade level (Biancarosa \& Snow, 2006). Because children are often reluctant to engage in literacy activities due to a lack of confidence (Guthrie, 2004), international innovative programs have been developed that pair reluctant readers with therapy dogs in schools and libraries. The philosophy of these programs is that dogs provide a non-judgmental audience that may offer a unique form of support for a child's learning (Jalongo, Astorino, \& Bomboy, 2004). The Intermountain Therapy Animals (I.T.A.) Association has hundreds of trained Reading Education Assistance Dogs and their owners working as "literacy teams" in schools and libraries in over 40 states in the U.S.A. (I.T.A., 2008). In Canada, organizations such as the Pet Therapy Society of Northern Alberta have developed a "Paws for a Story" program in Edmonton's public libraries (Kienholz \& Bailey Lindsay, 2006). To date, over 400 children in the Edmonton area have participated in this program. The popularity of the programs continues to grow, yet aside from promising pilot studies (I.T.A., 2007), very little research has explored the processes underlying how and why these programs work. Programs such as the I.T.A. in the United States report that their mission "is to improve the literacy skills of children through the assistance of registered therapy dogs as literacy mentors" (I.T.A., 2008). The term therapy dog, in the context of these programs, means that the dog is over one year of age, has completed basic obedience and temperance training, has veterinary certification of excellent health and is vaccinated, is well groomed, calm, and gentle (I.T.A., 2007). However, as I have written elsewhere, the term therapy dog implies that the dog is capable of treating maladjustment; therefore, a more appropriate term for the work that these animals do in the classroom context might be animal-assisted learning (Friesen, in press).

Numerous anecdotal reports by organizations such as the I.T.A., the Tales to Tails program, and Reading with Rover suggest that reading alongside a therapy dog can positively affect a child's reading. One such program was written about by a school library media co-ordinator (Briggs Newlin, 2003). In this program, 15 grade two students read aloud with a therapy dog for 20 minutes per week over one school year. Briggs Newlin states that "most participants improved their reading skills by at least two grade levels over the course of an entire school year" (p. 43). Many other small-scale reports have been written about animal-assisted reading programs (see for example Gerben, 2003; Hughes, 2002; Martin, 2001). Each article discusses 
programs established at local elementary schools in the United States that involve students reading for a 20-30 minute period per week with a trained therapy dog over one school year. In these reports, the R.E.A.D. Dogs Program used school reading scores to determine pre- and post-reading levels of students "in an effort to reduce bias towards its program," and so that "teachers can see the progress of kids who participate right alongside the rest of their classmates' results" (I.T.A., 2008). Although children's reading was reported to have improved through participation in these programs and in pilot projects (I.T.A., 2007), the paucity of publications in peer-reviewed journals examining these programs makes it difficult to determine the quality of these studies.

In this article I discuss research possibilities exploring how the inclusion of therapy dogs may support children's literacy learning in classrooms, particularly for students who are reluctant to engage in reading. I incorporate Guthrie and colleagues ${ }^{1}$ work in engagement into research in Animal Assisted Therapy (AAT) with children to posit a revised theory of engagement in the language learning classroom. Specifically, I explore how situational interest in a therapy dog (as compared to other animals) may inspire intrinsic motivation in literacy, how a therapy dog might foster social engagement (speaking and listening) during literacy activities in a supportive classroom environment, and how a therapy dog and its handler may uniquely support reading strategy instruction and practice. I have selected these aspects of Guthrie's and others' work because they are most conducive to illustrating possibilities for AAT in the elementary language arts classroom.

\section{Background and significance of Guthrie's work}

Guthrie, Wigfield, and Perencevich (2004) developed Concept-Oriented Reading Instruction (CORI) to foster literacy engagement in grades three, four, and five. CORI emphasizes context-specific student choice which encourages student ownership in learning, hands-on activities, a text-rich atmosphere, teaching comprehension strategies, and student collaboration and discussion during a reading and science unit on ecology. During the 2001 to 2005 school years, Guthrie and his colleagues engaged in a systematic series of research studies to investigate how CORI might foster positive gains in reading comprehension, reading motivation, and science knowledge. Guthrie et al. note that "for many years, reading researchers focused primarily on the cognitive aspects of reading" (p. 250); however, researchers are becoming increasingly interested in how motivation affects reading engagement. What is significant about Guthrie and his colleagues' work is the manner in which they attend to the cognitive perspective of reading as well as the sociocultural 
perspective by emphasizing not only the necessary role of strategy instruction but also the importance of peer socializing in language learning. As Stone (2006) acknowledges, "the cognitive science and sociocultural views of language are often more complementary than contradictory" (p. 11); it is the thoughtful combination of these two perspectives which may inform researchers and educators about how to best engage elementary language learners.

\section{What does it mean to be an engaged learner?}

Guthrie, Wigfield, and Perencevich (2004) define engagement as "the interplay of motivation, conceptual knowledge, strategies, and social interaction during literacy activities" (p. ix). The engaged reader is intrinsically and may be extrinsically motivated to read, is cognitively involved in the reading process, and is socially interactive. A motivated reader is a child who wants to learn and who has confidence in his/her ability to read, which in turn positively affects a child's perseverance when faced with literacy challenges.

Guthrie and his colleagues point out that we all have disengaged learners in our classrooms, and that as teachers, we know intuitively who they are. They describe disengaged students as the children who, despite being cognitively capable, rarely choose to read or volunteer to read aloud unless explicitly requested to do so by their teacher. When these children are asked to read, their answers in response to the text make sense, which shows that they are capable of comprehension. Often lacking confidence in their ability to read, these children may participate very little in peer group discussions. They will rarely engage in reading outside of school unless required to do so by their teacher, and will often then read reluctantly and sporadically. Although they typically are reading approximately one year below grade level, these children often do not qualify for special education. Guthrie and colleagues acknowledge that although many children come to school excited about learning, some children's enthusiasm for school wanes for reasons such as, but certainly not limited to, repeated negative experiences with reading or a growing sensitivity to peer comparison, possibly in combination with negative teacher feedback. Still other children may disengage due to the predictable nature of school schedules, in which learning has become repetitive and mundane.

\section{Why is engagement important in the language arts classroom?}

Guthrie et al. (2004) assert that engaged readers are higher achievers in school; when students are engaged, reading improves. They note that "engagement 
and reading are reciprocal" (p. 6). Stanovich's (1986) "Matthew Effect" asserts that the more students engage in reading, the more opportunities they have to improve fluency, word recognition, and vocabulary. Engaged readers benefit from opportunities to discuss texts in relation to their own experiences and learn about texts in many genres and forms in both fiction and non-fiction (Pinnell, 2009). In contrast, students with limited engagement with text do not benefit from repeated opportunities to develop and expand reading skills and may therefore fall further and further behind their peers.

Despite wide recognition of this spiral effect in reading research, Guthrie et al. (2004) articulate that there is a lack of research exploring the "refined, empirical understanding about classroom practices that promote engagement" (p. 1). In response to this need, they argue that researchers should "identify and understand educational conditions that will foster reading engagement [and to accomplish this], we must try out new educational ideas in the classroom" (p. 20). This call for innovation in reading instruction is supported by McCormick Calkins (2001) who suggests that educators need to do more than simply collect new methods, but weave a sense of "vision, passion and grace" (p.4) into teaching while taking into consideration children's interests. In so doing, it will become possible to "re-envision literacy learning" (Guthrie et al., 2004, p. 26) in schools. It is in this spirit of re-imagining literacy in the elementary school classroom that I turn now to one possibility previously overlooked: how a therapy dog might inspire children to engage in classroom literacy activities.

\section{Motivation to Read:The Situational to General Hypothesis}

After that first day, the students and I agreed that Tango would be able to visit our classroom for one morning each Friday. We agreed that the students could sign up for ten minutes of individual or paired "Tango Time" during a one-hour period, during which the students could choose to play with Tango, or sit quietly and talk or read to her. Over time, it seemed that my students' interest in Tango united them in a common and authentic purpose for learning, and therefore served as the springboard for numerous other literacy-based activities. For example, one reading and writing project evolved out of what seemed to be my students' protection of Tango and their observations of and interactions with other children. Because we had been learning how to care for a dog, the similarities and differences between human needs and a dog's needs had become quite clear for my students. Their concern was that children in other classes didn't understand these 
concepts as well as they were coming to understand them themselves. Therefore, we decided that the best way to attend to this might be to teach others about what we had learned.

First, the students selected topics that they were interested in such as ways to approach a dog you don't know, feeding a dog, how to know if a dog is afraid or stressed, teaching a dog how to do a trick, and bathing a dog. Then, while referring to lessons and books we had read and discussed and searching pre-selected sites on the Internet with the assistance of their grade four book buddies, the students worked in pairs and small groups to develop posters (including both visuals and text information) about their topic. We then invited other classes, parents, and siblings to an information fair about dogs. This evolved into student requests to also "research" other animals and eventually other personal interests. It seemed that what began as a purposeful and meaningful situational interest in Tango then inspired many of my students to continue to read, write, learn and teach others about other topics of importance to them.

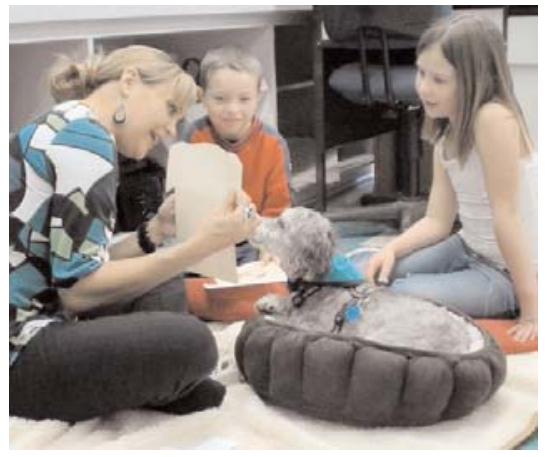

Fig. 1: Reading time with a trained and certified therapy dog
It is not difficult for educators to envision how children's interest in reading might be engaged if given novel or situational opportunities to learn about and interact with a therapy dog in the classroom context. Guthrie et al. (2004) define situational interest as "a temporary, affective reaction to an activity or a set of conditions, a reaction that may not last" ( $p$. 268). However, Guthrie and colleagues note that "if the energy aroused by fascinating phenomena is directed into texts, engagement in reading increases" (p. 79).

They propose that the initial excitement of a "situational interest ... can develop into long-term motivation for reading" (p. 79). Guthrie et al.'s situational to general hypothesis is supported by Dewey's (1963) theory of educative experiences. Dewey's theory is grounded in the idea that "all genuine education comes about through experience" (p. 25), but that the quality of the experience determines both the "immediate aspect of agreeableness or disagreeableness, and ... its influence upon later experiences" (p. 27). Dewey argues that "every experience lives on in other experiences" (p. 27), similar to how a situational interest in a specific topic may then "live on" through a more general fascination in future experiences with books on related topics. Guthrie et al. (2006) sought to explore how a stimulating situational interest might 
"encourage the development of long-term individual interest in reading" (p. 232). The grade three students in Guthrie et al.'s 2006 study were engaged in a 12-week reading and science unit on ecology which provided numerous opportunities for handson, stimulating learning. "The two intervention groups compared in this study were students in classrooms that provided a high number of stimulating reading activities and students in classrooms that had a low number of stimulating reading activities" (p. 235)."All classes participated in one to four science investigations that included an owl pellet dissection, observation of guppy behaviour, an experiment on guppy defense, and an observation of a predatory diving bug" (p. 235). Reading comprehension was evaluated using a tool designed specifically for this project as well as a standardized reading achievement test, and motivation was analyzed using a student self-report measure and teacher's ratings of student motivation using the Motivation for Reading Questionnaire (MRQ;Wigfield \& Guthrie, 1997). Through systematic statistical analysis, the authors concluded that the "number of stimulating tasks increased motivation for reading, which was associated with increased reading comprehension on the standardized test" (p. 242).

The conclusions of this study are particularly significant for children whose reading motivation seems to decline as they progress through elementary school because the study authors suggest that a decline in reading motivation is not unavoidable or irreversible. Instead, capturing students' curiosity through situational interest activities may lead to generalized motivation towards reading in a supportive classroom context. Dewey (1963) would define this influence of past experiences on those in the future as the continuity of experience; "every experience both takes up something from those which have gone before and modifies in some way the quality of those that come after" (p. 35). Therefore, a child's initial curiosity in a topic may affect and encourage student participation in future positive, quality educative experiences. Guthrie et al. (2004) suggest that situational interest can become deeper personal interest by "creating specific classroom environmental conditions that foster this interest" (p. 268).

Along with a deep, personal interest in reading, a main goal of literacy teachers is to develop a classroom characterized by a "sense of joy, playfulness, enthusiasm, and intention" towards text (Collins, 2008, p.xv). In the classroom context with a therapy dog, this sense of interest, enthusiasm, and intention might be encouraged by, but is not limited to, the example of the information fair about dogs and/or other animals given at the beginning of this section. Inspired by the developing relationship between students and the therapy dog, the teacher can direct students' attention towards other creative literacy projects incorporating the six strands of language 
arts: reading, writing, speaking, listening, viewing, and representing. Because "all the language arts are interrelated and interdependent, facility in one strengthens and supports the others" (Alberta Learning, 2000). For example, in our classroom, the students self-published illustrated stories about Tango (and later about other animals they loved):

First, we took pictures of Tango and then, using the photos as a reference, we drew portraits of her. I incorporated an art lesson into this period of language arts whereby the children were taught how to use light and shadow to make their portraits more realistic. They were also thrilled to have the "real Tango" present to refer to as they drew and painted. The children were encouraged to then place their portrait of Tango in any setting they wanted to. After telling stories and brainstorming ideas with their book buddies about what Tango might do if she were in that setting, they wrote, edited, revised, and eventually published stories for our school library about the imaginative "Adventures of Tango." One of my students wrote a story about Tango as a professional hockey player on his team (he even gave her her own equipment and hockey stick in his picture); another dressed Tango in a pink tutu in her illustration, placed her on stage in a great hall and wrote the story of Tango as a prima-ballerina. Still other children chose to incorporate their own pets (or Grandma's cat or their cousin's gerbil) into their stories either in addition to Tango or in place of her. Laughter and excitement characterized the atmosphere of our classroom during this project; I beamed when my students would beg for more time to write.

\section{A guppy versus a puppy: an important difference?}

Guthrie et al. (2004) note that they selected topics from the science curriculum as the focus for their studies on reading engagement because they often stimulate children's situational interest and invite hands-on learning. I propose that it is no accident that the examples given in their work involve animals as motivators for encouraging situational interest in students' reading. Dewey (1963) stresses the importance of selecting "the kind of present experiences that live fruitfully and creatively in subsequent experiences" (p. 28). Likely because of elementary students' common fascination with the natural world, Guthrie and his colleagues (2006) include "observation of guppy behaviour" as a way to encourage situational interest in grade three students. Through this example, I consider why dogs may be a particularly suitable choice for sparking children's situational reading motivation. How is observing a guppy similar to or different from observing a puppy?² Guppies and puppies are both live animals that can be observed. Both animals rely upon humans in captivity for their survival and provide genuine opportunities for children to learn 
about the life cycle. Both animals offer possibilities to teach children about the responsibility of caring for another living thing, and to develop empathy for a living animal's unique needs. However, there are important differences in the nature of interaction between children and these two animals which, taken together, highlight the significance of incorporating a dog into literacy activities.

\section{Multisensory Experience, Oral Language, and Cognition}

"A dog can express more with his tail in minutes than his owner can express with his tongue in hours." - Anonymous

Although many animals can be observed, it is both possible and probable that children will not only observe a dog, but over time, will also physically interact with it. Guthrie et al. (2004) speak to the importance of multi-sensory experiences "in which students see, hear, feel, smell, and touch ... the physical environment for purposes of inquiry" (p.62) in motivating situational interest. Moreover, research exploring interactions between children and animals seems to indicate that children prefer to touch furry animals (Nielsen \& Delude, 1989), and conversation with children while interacting with a small animal seems to invite questioning, personal stories, and naturally occurring "teachable" moments (Hunt \& Hart, 2001). This research seems to suggest that when children are provided opportunities for multi-sensory interaction with animals, including touch, they may be more likely to engage in cognitive thinking processes such as questioning, and may be more likely to relate the encounter to their own experiences than when viewing an animal either through glass or from a distance.

\section{Connection with language}

"Dialogue with [animals] offer a time-out from the anxieties of human exchange ... Despite most children's acknowledgement that pets cannot literally comprehend what they are saying, children have the feeling of being heard and being understood." (Melson, 2001, p. 51)

Puppies, unlike most other domesticated animals, have a unique relationship with spoken language in both their capacity and desire to understand language, 
and their expressiveness in response to human requests. To children's delight, most dogs are highly trainable, and can respond to requests such as "sit" or "shake a paw" or to questions such as "Do you want a treat?" or "Should we go for a walk?" Particularly when they are spoken to on a regular basis, dogs can also respond to changes in voice inflection and volume, for example, by cocking their head or wagging their tail. Because children can observe a dog's understanding of language, they may feel more of a connection or bond with a dog compared to many other animals, particularly when reading to them, because there is potential for the dog to "listen" to the story despite the fact that dogs cannot read themselves. Hart (2006) refers to dogs and cats as "conversational partners," despite the fact that they cannot verbally interact, by noting how many people speak to their dog (Rogers et al., 1993 as cited in Hart, 2006) and how dogs can be catalysts for friendly conversations among people who are relative strangers. However, even more than as a conversational partner, perhaps a dog's inability to speak, to criticize or judge, allows children to perceive them as the most supportive communicators of all. In fact, in the many cards and letters Tango received from past encounters with children in classrooms, the recurring comment in children's writing has been to thank Tango for being "such a good listener."

\section{Social Nature, Social Response, and Loyalty}

"Dogs love company. They place it first in their short list of needs."

- J.R. Ackerley (as cited in Wright, 2009)

Unlike many other animals' apparent lack of interest in human beings, dogs are instinctually social and prefer to be members of a group. When this group is a classroom of children, dogs may, over time, become increasingly interested and responsive to the children and become willing participants in children's daily classroom activities. For many children, but particularly for the child who lacks confidence, a dog's consistently happy disposition and willingness to be near the child may help him or her to feel important and needed in this relationship. In my own classroom, it was fascinating to observe what seemed to be Tango's increasingly enthusiastic greeting towards students she came to know well over several months of class visits. In return, I observed children seeking Tango out when it seemed that they needed a hug or some comfort themselves. As acknowledged by Brendtro and Long (1995), classrooms can be stressful places for children due to a combination of academic expectations and social pressures to "fit in." The developing relationship between students and the dog may serve as a source of solace and calm within the complex social network of the classroom. 


\section{Expressiveness}

In contrast to many other animals, dogs' expressions are animated and thus may ignite children's imaginations; whether or not dogs actually have unique personalities, many children and adults transfer human characteristics onto dogs. For example, we might say "Oh, look at the way he is laying there. I think he's feeling sad!" If a dog is able to capture students' imaginations, it is possible that stories about dogs and/or other animals may also become more appealing. Perhaps all of these differences between puppies and guppies taken together suggest that "man's best friend" may also be child's best friend in the literacy classroom. In a quantitative review of 37 peer-reviewed AAT studies, Nimer and Lundahl (2007) found that dogs were most often included in studies with children between 0-12 years, and dogs were associated with positive behavioural, emotional/social, or medical benefits for children in every study. I propose that incorporating therapy dogs into language learning lessons in what may begin as a situational interest has tremendous potential to develop into general motivation towards reading.

\section{Social Engagement in a Supportive Classroom Environment}

Guthrie (2004) clarifies that "at the heart of engaged reading is the notion that participation is a key to proficiency" (p. 8). Therefore, if disinterested readers choose to participate, this greatly increases the likelihood that they will become more proficient readers. Guthrie et al. (2004) explain that when children work together, "the whole class becomes a learning community, sharing what they have learned and asking further questions about it" (p. 269). Guthrie and colleagues (2004) emphasize that, when given opportunities to collaborate with others, students "use their social network to undergird their understanding and to enhance their enjoyment in learning from books" (p. 58). Further,

[b]y explaining new knowledge to a peer, a student participates in the process of socially interacting to form new knowledge structures from text. The process of battling out the meaning of a text, and assuring full coverage of its content in deciding about the interpretation of material, enables children to learn from the art of social interchange and dialogue in a literacy situation. 
Although research which examines social support usually only considers ways in which humans interact with each other (Melson \& Fine, 2006), studies exploring the social and emotional effects that interacting with therapy dogs has on children in special-needs classrooms suggests that therapy dogs may be able to assist in encouraging positive communication (or speaking and listening) in the language arts classroom. Because "oral language is the foundation of literacy" and because it is through "listening and speaking [that] people communicate thoughts, feelings, experiences, information and opinions, and learn to understand themselves and others" (Alberta Learning, 2000), possibilities for how a therapy dog might encourage verbal communication in the classroom may be significant for children's learning. For example, a study by Anderson and Olson (2006) determined that because the children in their study viewed the dog as a non-judgemental "friend" in the classroom, interacting with the dog seemed to encourage positive communication between students. These authors suggest that dogs may have a calming effect on children aged six to eleven years by modelling acceptance, affection, and trust. A second study examining the short-term effects of a therapy dog on children's state of mind determined that interactions with a dog "increased to a large extent the alertness and attention of the child," and "caused more openness and desire for social contact and exchange" (Prothmann, Bienert, \& Ettrich, 2006, p. 275). The authors note that

animals seem to be able to cause a profound change in the atmosphere ... leading to the above-mentioned changes in subjective experience and selfperception. The children and adolescents may feel transported into an atmosphere that is characterized by warmth, acceptance, and empathy. (p. 275)

The change in atmosphere attributed to the animals by Prothmann et al. (2006) may have profound implications for the elementary language arts classroom. Literacy educators have long been aware of how the classroom environment can either enhance or detract from learning. Cambourne's (1988) conditions for literacy learning emphasize that children need to feel safe to take risks in order for learning to occur, and that a young learner's literacy attempts must be "enthusiastically, warmly, and often joyously received" (p. 37). Collins (2004) acknowledges that particularly because "children in the primary grades are still so new at school, we need to provide the kind of safe environment where they'll be willing to face challenges and take on risks" (p. 5). Both Cambourne (1988) and Collins (2008) emphasize the importance of caring, genuine relationships between teacher and learners, and that educators need to pay careful attention to the conditions in which engagement occurs in their classrooms. "Experience does not go on simply inside a person" (Dewey, 1963, p. 39); therefore, educators commonly attend to the environment, or the "sources 
outside an individual which give rise to experience" (p. 40). Particularly because our goal as literacy educators is to encourage children's love of reading, as students develop literacy skills in the classroom, "collateral learning in the way of formation of enduring attitudes, of likes and dislikes, may be and often is much more important than the spelling lesson" (p. 48) or other content matter at hand. What kinds of collateral learning takes place when children interact with a therapy dog during literacy activities? How might interaction with a therapy dog enhance the literacy learning environment? How do children perceive these experiences? What might be the significance of these experiences for children who are learning to read? An exciting area of future research may be to explore possibilities for how interacting with a therapy dog may positively influence students' collateral literacy learning and encourage students to take risks during oral literacy activities in the elementary language arts classroom. The following experience illustrates possibilities for increased social engagement within a positive classroom environment when a therapy dog and handler are incorporated into literacy activities:

I left classroom teaching after eight years to pursue my PhD, but I wanted to continue to explore how a therapy dog might be incorporated into other classrooms and at other grade levels. Therefore, Tango and I began volunteering with a local pet therapy organization after undergoing the required screening and training process. So many questions remained: Had my own students only been enthralled with Tango because of my own love for my pet? Would students older than grade two be interested in having my little dog and I visit their classroom?

Not long after receiving our certificate of completion for pet therapy training, Tango and I were invited to volunteer in a grade seven/eight class of students. The teacher wanted us to visit her classroom in part because she was very afraid of dogs, and she wanted to model how to eventually overcome fear for her students by facing it. In addition, she had heard about my experience working with my dog in my own classroom and was intrigued by the possibilities for incorporating a dog into literacy activities. We agreed that her students would be invited to sign up for "Tango Time" just as my own students had been. During this time the students could choose any book they liked to read aloud to Tango.

On one particular afternoon, a young lady named $\mathrm{Kim}^{3}$ had her turn to read to Tango. On this afternoon, Kim was sitting in the corner in tears. Although doubtful that she would respond, Kim's teacher gently asked if she would like to come to read to Tango. To her teacher's surprise, Kim not only came directly over but was also ready to read as she wiped away the tears rolling down her face. As she read to Tango, Kim positioned the book so Tango could see the pictures, and she laughed throughout the entire story. I asked both 
Kim and Tango questions while Kim read, and at the end of the story I explained to the teacher that we had learned three new words - and Kim proudly told her what they were. This experience suggests that by involving Tango we were not only able to help turn around an upsetting situation, but that Kim had been calm and involved enough to retain what she had learned during the reading. Tango, for her part, continually kissed away Kim's tears where they had fallen on her hands and arm, to which Kim giggled in response. It seemed like such a little thing, but it must have made Kim feel very special because in her words she knew that "Tango cared" about her.

As I reflected on this experience, I wondered: Would Kim have chosen to engage in reading if Tango hadn't been there? How might Tango have supported her reading efforts in a way that I couldn't have? What kinds of collateral learning may have been taking place during this experience, and how might reading with Tango "live on" in future reading experiences for Kim? Is this an example of the "enthusiastic, warm, and joyous" response to a reader's efforts that Cambourne writes about? Or was it something more thanother than-this?

\section{The Unique Role of the Dog and Handler in Strategy Instruction}

Because strategy instruction and practice can increase reading frequency (Wigfield et al., 2004), which can then lead to increases in vocabulary, word recognition, and fluency (Stanovich, 1986), the therapy dog's handler and the dog may work as a team under the teacher's direction, when reading with children either individually or in small groups, to offer a unique form of support in children's learning. Although simply having another adult in the classroom does increase opportunities for additional support for children in practicing their reading strategies, the dynamics among child, adult, and dog are unique in this context. Therapy dog handlers can be "enthusiastic facilitators of each child's reading practice," and "are encouraged to pay attention ... and offer assistance when necessary" (Jalongo, 2005, p. 154). Literacy research suggests that caring and enthusiastic support of a child's reading efforts by an adult volunteer will likely contribute to literacy development for the child (Pressley, 2001), and that one-on-one, regularly scheduled mentorship opportunities with an emphasis on the quality of the relationship between the adult and child as well as on academics can positively affect a child academically, socially, and emotionally (Dappen \& Isernhagen, 2006; Ellis, Small-McGinley, \& de Fabrizio, 2001; Randolph \& Johnson, 2008). Within animal-assisted literacy sessions, the therapy dog handler 
does not rely upon a pre-established reading program to guide his or her interactions with the child. Instead, in line with best practice in literacy instruction, he or she offers responsive assistance guided by the child's unique questions and struggles as he or she reads (McCormick Calkins, 2001). As Harwayne (2000) notes, otherwise "joyful teaching moments" can be lost in the institutionalization of the teaching of reading when adults in children's lives become "fearful of sharing in the wrong way" (p. 200).

Within small group reading sessions, the therapy dog can "act as an intermediary as the handlers check the child's understanding and even ask young readers to explain [vocabulary] to the dog" (Jalongo, 2005, p. 154). As highlighted by McCormick Calkins (2001), the instruction most valuable for young learners is that which comes from observations of what they are doing already. Vygotsky $(1978 ; 1986)$ explains this kind of instruction as working within a child's zone of proximal development, or working with the child to comprehend that which would be difficult for the child to understand without assistance. For example, upon observing that a child is struggling with a word, the handler might say “Tango doesn't know this word either. Maybe we can work it out together?" If the handler wants to check that a child comprehends the meaning of a word, he or she might say, "Tango doesn't know what that big word means. Do you think you can explain it to her?" At the end of the reading session, the handler might highlight how the child has learned and perhaps taught Tango three new words today (as was illustrated in the example earlier in Kim's story). Encouraging the child to be the one to teach may reverse traditional power roles of the adult and child. In so doing, the child may realize that, for the first time, he/she knows more than the other member of the group (the dog), which in turn may help to increase the self-confidence and willingness of a reader otherwise reluctant to engage.

\section{Concluding Remarks}

Although further research is required, there seems to be strong potential for how a therapy dog might inspire student literacy engagement in the elementary language arts classroom. Therapy dogs may be able to capture the situational interest of children because they offer a multi-sensory learning experience, are highly sociable and responsive to humans, and possess a capacity for limited comprehension of oral language. Over time, the initial excitement of learning about and/or reading to the dog may develop into long-term intrinsic motivation to read through related stimulating, hands-on reading, writing, oral, and collaborative literacy activities about dogs 
and other animals. Research in AAT suggests that incorporating dogs into learning environments provides opportunities for social engagement which can enhance children's understanding, enjoyment, and interpretation of text in the language learning classroom. Further, the unique role of the handler in strategy instruction and practice, characterized by a shift in power relations between adult and child, may help to increase students' confidence and willingness to engage in reading. Guthrie et al. (2004) emphasize that "engagement in reading is crucial for the development of lifelong literacy" (p. ix). Perhaps it is time that we begin to re-imagine pedagogical possibilities which may not yet be mainstream in our school culture for the sake of students who have, until now, chosen not to engage in literacy.

\section{Notes}

1. The work referred to in this article includes the following studies as indicated in the reference list: Guthrie, 2004; Guthrie, Hoa, Wigfield, Tonks, \& Perencevich, 2006; Guthrie, Wigfield, Humenick, Perencevich, Taboada, \& Barbosa, 2006; Guthrie, Wigfield, \& Perencevich, 2004; Wigfield, Guthrie, Tonks, \& Perencevich, 2004.

2. It should be noted, however, that puppies - or dogs under one year of age-are not permitted to be therapy dogs because of their naturally exuberant behaviour; I use the word "puppy" here lightly.

3. The name of the student has been changed to protect her identity.

\section{References}

Ackerley, J. R. (1956). My dog Tulip. New York: New York Review of Books. As cited in Wright, H.N. (2009). My faithful companion. Eugene, OR: Harvest House Publishers.

Alberta Learning (2000). Retrieved on September 10, 2009 from the Government of Alberta Education Web site: http://education .alberta.ca/media/450519/elak-9.pdf
Anderson, K. L., \& Olson, M. R. (2006). The value of a dog in a classroom of children with severe emotional disorders. Anthrozoos, 19(1), 35-49.

Biancarosa, C., \& Snow, C. E. (2006). Reading next - A vision for action and research in middle and high school literacy: A report to Carnegie Corporation of New York ( $2^{\text {nd }}$ ed.). 
Washington, DC: Alliance for Excellent Education.

Brendtro, L., \& Long, N. (1995). Breaking the cycle of conflict. Educational Leadership, 52(5), 52-56.

Briggs Newlin, R. (2003). Paws for reading. School Library Journal, June, p. 43.

Cambourne, B. (1988). The whole story: Natural learning and the acquisition of literacy in the classroom. Auckland, NZ: Ashton Scholastic Ltd.

Collins, K. (2004). Growing readers: Units of study in the primary classroom. Portland, ME: Stenhouse Publishers.

Collins, K. (2008). Reading for real: Teach students to read with power, intention, and joy in $\mathrm{K}-3$ classrooms. Portland, ME: Stenhouse Publishers.

Dappen, L., \& Isernhagen, J. (2006). Urban and nonurban schools: Examination of a statewide student mentoring program. Urban Education, 41(2), 151-168.

Dewey, J. (1963). Experience and education. New York: Macmillan Publishing.

Ellis, J., Small-McGinley, J., \& De Fabrizio, L. (2001). Caring for kids in communities. New York: Counterpoints.

Friesen, L. (in press). Exploring animal-assisted programs in school and therapeutic contexts. Early Childhood Education Journal.

Gerben, R. (2003). Kids + dogs = combination for paw-rrific reading adventures. Interactions, (21)2, 4-12.

Guthrie, J. (2004). Teaching for literacy engagement. Journal of Literacy Research, 36(1), $1-29$.

Guthrie, J., Hoa, L., Wigfield, A., Tonks, S., \& Perencevich, K. (2006). From spark to fire: Can situational reading interest lead to long-term reading motivation? Reading Research and Instruction, 45(2), 91-117.

Guthrie, J., Wigfield, A., \& Perencevich, K. (2004). Motivating reading comprehension. Mahwah, NJ: Lawrence Erlbaum Associates.

Guthrie, J., Wigfield, A., Humenick, N., Perencevich, K., Taboada, A., \& Barbosa, P. (2006). Influences of stimulating tasks on reading motivation and comprehension.
The Journal of Educational Research, 99(4), 232-245.

Hart, L. A. (2006). Community context and psychosocial benefits of animal companionship. In A. H. Fine (Eds.) Handbook of animal-assisted therapy: Theoretical foundations and guidelines for practice ( $2^{\text {nd }}$ ed., pp. 73-94). San Diego, CA: Elsevier.

Harwayne, S. (2000). Lifetime guarantees: Toward ambitious literacy teaching. Portsmouth, $\mathrm{NH}$ : Heinemann.

Hughes, K. (2002). See spot read. Public Libraries, November/December, 328-330.

Hunt, S., \& Hart, L. (2001). Role of small animals in social interactions between strangers. The Journal of Social Psychology, 132(2), 245-256.

Intermountain Therapy Animals (2007). Reading education assistance dogs (R.E.A.D.) training manual. Salt Lake City, UH: Intermountain Therapy Animals.

Intermountain Therapy Animals (2008). Reading education assistance dogs: A program of the intermountain therapy animals. Retrieved January 31, 2009, from http://www.thera pyanimals.org/read/article130.html.

Jalongo, M. R. (2005). What are all these dogs doing at school? Using therapy dogs to promote children's reading practice. Childhood Education, 81(3), 152-158.

Jalongo, M., Astorino, T., \& Bomboy, N. (2004). Canine visitors: The influence of therapy dogs on young childrens' learning and well-being in classrooms and hospitals. Early Childhood Education Journal, 32(1), 9-16.

Kienholz, B., \& Bailey Lindsay, L. (2006, Winter). PAWS for a story: Doggone good reading fun! Letter of the $L A A, 9$.

Martin, S. (2001). R.E.A.D. is a pawsitive program for kids of all ages. Interactions, (19)3, 10-11.

McCormick Calkins, L. (2001). The art of teaching reading. New York: Longman.

Melson, G. F. (2001). Why the wild things are. Cambridge, MA: Harvard University Press.

Melson, G. F., \& Fine, A. H. (2006). Animals in the lives of children. In A. H. Fine (Eds.) Handbook of animal-assisted therapy: 
Theoretical foundations and guidelines for practice (2nd ed., pp. 207-226). San Diego, CA: Elsevier.

Nielsen, J., \& Delude, L. (1989). Behavior of young children in the presence of different kinds of animals. Anthrozoos, 3, 119-129.

Nimer, J., \& Lundahl, B. (2007). Animal-assisted therapy: A meta-analysis. Anthrozoos, 20(3), 225-238.

Pinnell, G. S. (2009). When readers struggle: Teaching that works. Portsmouth, $\mathrm{NH}$ : Heinemann.

Pressley, M. (2001). Effective beginning reading instruction. Executive Summary and Paper Commissioned by the National Reading Conference. Chicago: National Reading Conference.

Prothmann, A., Bienert, M., \& Ettrich, C. (2006). Dogs in child psychotherapy: Effects on state of mind. Anthrozoos, 19(3), 265-277.

Randolph, K. \& Johnson, J. (2008). School-based mentoring programs: A review of the research. Children \& Schools, 30(3), 177-185.
Stanovich, K. (1986). Matthew effects in reading: Some consequences of individual differences in the acquisition of literacy. In R. B. Ruddell \& N. J. Unrau (Eds.), Theoretical models and processes of reading. ( $5^{\text {th }}$ ed., pp. 454-516). Newark, DE: International Reading Association.

Stone, C.A. (2006). Contemporary approaches to the study of language and literacy development. In C. Addison Stone, E.R. Silliman, B. J. Ehren, \& K. Apel (Eds.), Handbook of language and literacy, (pp. 3-24). New York: The Guilford Press.

Vygotsky, L. (1978). Mind in society. Cambridge, MA: Harvard University Press.

Vygotsky, L. (1986). Thought and language (A. Kozulin, Trans.). Cambridge: The Massachusetts Institute of Technology.

Wigfield, A., \& Guthrie, J. (1997). Motivation for reading: Individual, home, textual, and classroom perspective. Educational Psychologist, 32, 57-135.

Wigfield, A., Guthrie, J., Tonks, S., \& Perencevich, K. (2004). Children's motivation for reading: Domain specificity and instructional influences. The Journal of Educational Research, 97(6), 299-309.

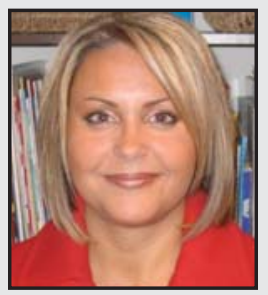

Lori Friesen is a full-time PhD student in Elementary Education at the University of Alberta. She earned her Masters in Education at the University of Lethbridge and wrote The Beginning Teacher's Handbook for Elementary School as the final project for her degree. In addition to teaching in Hong Kong and Japan, Lori taught elementary school for seven years and taught one year in The Faculty of Education at the University of Lethbridge. 